\title{
A shorter treatment regimen for latent tuberculosis infection holds promise for at-risk Canadians
}

\author{
C Pease ${ }^{1}$, KR Amaratunga ${ }^{2,3}$, GG Alvarez ${ }^{1,3,4 *}$
}

\section{Abstract}

Despite recent success in reducing its incidence, tuberculosis remains a considerable challenge in Canada, particularly among foreign-born and Indigenous populations. A key component of the strategy for controlling the disease is the treatment of latent tuberculosis infection (LTBI). The standard treatment consists of isoniazid (INH) daily for nine months. In recent years, shorter regimens have been developed in the hope of increasing rates of treatment acceptance and completion. Of these, the shortest and most recently developed is a combination of INH and rifapentine taken once weekly for 12 doses (3HP), typically using directly observed therapy. This regimen has been approved by the Food and Drug Administration in the United States but is not yet authorized for use in Canada.

Based on a rapidly expanding number of observational studies and randomized controlled trials, 12 weeks of $3 \mathrm{HP}$ appears to have similar efficacy to nine months of INH, a favourable adverse event profile and potentially improved rates of treatment completion. Although rates of treatment acceptance, the role of self-administered therapy and the regimen's cost-effectiveness within the Canadian context remain uncertain, 3HP is a promising alternative to existing treatments for LTBI.

\author{
Affiliations \\ 1 Division of Respirology, \\ University of Ottawa, Ottawa, ON \\ ${ }^{2}$ Centre for Communicable \\ Diseases and Infection Control, \\ Public Health Agency of Canada, \\ Ottawa, ON \\ ${ }^{3}$ Department of Medicine, \\ Division of Infectious Diseases, \\ University of Ottawa, Ottawa, ON \\ ${ }^{4}$ Ottawa Hospital Research \\ Institute, Ottawa, ON
} *Correspondence: galvarez@
ohri.ca

Suggested citation: Pease C , Amaratunga KR, Alvarez GG. A shorter treatment regimen for latent tuberculosis infection holds promise for at-risk Canadians. Can Commun Dis Rep. 2017;43(3):67-71.

https://doi.org/10.14745/ccdr.v43i34a02

\section{Introduction}

Although the incidence of active tuberculosis (TB) in Canada has gradually declined over the past decade, the disease remains a major health challenge that disproportionately affects marginalized populations (1). The burden of the disease- $90 \%$ of active cases-falls on the foreign-born populations and Canadian-born Indigenous people (1). In 2014, 69\% of reported new cases of active TB in Canada occurred in the migrant population where the incidence rate was $13.7 / 100,000$ (1). Among First Nations, who comprise the majority of Canadian-born Indigenous people, the incidence rate was even higher at 19.3/100,000 (1). However, the highest rate of active TB in Canada was reported among the Inuit, with an incidence of 198.3/100,000, a rate over 300 times that of the Canadian-born, non-Indigenous population (1). In fact, this rate is similar to that of the TB burden in developing countries such as Afghanistan, Ethiopia and Bangladesh (2).

The World Health Organization has set an ambitious strategy to end the global TB epidemic by 2035 . They defined the end as reaching a global incidence rate of fewer than 100 cases per million population (3). A vital component of the overall approach to eliminating TB is reliable testing and effective treatment of latent tuberculosis infection (LTBI) to prevent active disease in at-risk populations (3). LTBI occurs when individuals are exposed to infectious active TB and their immune system sequesters viable Mycobacterium tuberculosis bacilli but does not lead to active disease (4). While neither infectious nor symptomatic, those with LTBI carry a 5\%-15\% lifetime risk of developing active TB from reactivation of the sequestered bacilli (5). Clinically, LTBI is diagnosed by either a positive tuberculin skin test (TST) or a positive interferon-gamma release assay (IGRA), in the absence of active disease (6). Although neither of these tests represent a gold standard, they are the recommended tests for the diagnosis of LTBI in Canada (6).

\section{Treatment of latent TB infection}

Treatment of those with LTBI reduces the risk of developing active disease by $60 \%-90 \%(7)$, which in turn prevents ongoing transmission (8). Although treatment efficacy in preventing active TB is one important aspect in the selection of a treatment regimen, it is not the only factor to consider. The goal of therapy is to reduce the individual risk of developing active TB and to reduce TB transmission within populations. Other important considerations include anticipated rates of acceptance (the proportion of those offered treatment who initiate the treatment) and completion (the proportion of those who accept treatment who finish the treatment). Adverse effects are also of central importance, particularly since LTBI treatment is usually given to healthy patients in the hopes of preventing disease. Finally, the cost effectiveness of the regimen in comparison to other competing interventions must be evaluated. 
The current international and Canadian standard for the treatment of LTBI is nine months of daily isoniazid (INH9) (6). However, the prolonged duration of this treatment may hinder completion of therapy (9). One shorter-course option is rifampin (RMP) given daily for four months. This regimen has been shown to be as safe as INH9 and to improve the adherence rate, but its effectiveness is less well established $(10,11)$. A multicentre, multinational randomized controlled trial to be completed shortly compares the effectiveness of RMP and INH9 (12). Another alternative is a combination of INH and RMP given daily for 3-4 months. This regimen likely has a safety and efficacy profile similar to INH-based regimens $(13,14)$.

However, even these shorter-course regimens require adherence to daily therapy for several months. A newly developed regimen consists of a combination of INH and rifapentine given once weekly for 12 doses (3HP). Rifapentine was initially developed as a treatment for active TB in the 1970s and early 1980s (15), but its use by HIV patients for the continuation phase of active TB treatment demonstrated rates of treatment resistance higher than that of rifampin (16). As such, rifapentine is not recommended for use in active TB in Canada (17). Nonetheless, it is an effective short-course treatment option that requires by far the fewest doses of any regimen. This regimen was recently approved for the treatment of LTBI by the United States Food and Drug Administration but it is not yet authorized for use in Canada.

\section{Treatment efficacy}

The first randomized controlled trial (RCT) to evaluate $3 \mathrm{HP}$ for LTBI was published in 2006 (18), over 20 years after the development of rifapentine (15). As with other more recent RCTs, 3HP was tested using directly observed therapy (DOT) (18-21). This trial, which compared $3 \mathrm{HP}$ to a regimen of two months of daily RMP and pyrazinamide, showed comparable efficacy in preventing active TB and lower rates of adverse effects with $3 \mathrm{HP}$ (18). Note that RMP/pyrazinamide is no longer recommended for LTBI treatment because of the increased risk of severe liver injury and death compared to INH (6). A subsequent trial conducted in HIV patients showed the efficacy of 3HP, INH given for six months, INH given continuously for up to six years and a combination of INH and RMP given for 12 weeks to be comparable (19). These findings prompted the PREVENT TB trial, a large multicentre non-inferiority RCT that compared directly observed 3HP and self-administered INH9 (20). The trial included nearly 4,000 patients per arm and demonstrated the non-inferiority of 3HP compared to INH9 (20). To the best of our knowledge, no trials comparing self-administered $3 \mathrm{HP}$ to INH9 have been published. A follow-up study to the PREVENT TB trial that focused on the pediatric population showed similar results (21). Furthermore, a 2013 Cochrane review (22) and a recent network meta-analysis support the efficacy of 3HP (14). An earlier network meta-analysis published in 2014 did not find a statistically significant benefit of $3 \mathrm{HP}$ in preventing active TB compared to other regimens, but interpretation of this study is complicated by the inclusion of numerous studies that did not confirm LTBI (23).

\section{Treatment acceptance and completion}

Because acceptance of treatment cannot accurately be determined in randomized trials (given that patients accept entry into the trial rather than a specific regimen), data are limited to observational studies. Unfortunately, rates of treatment acceptance are often low. In a study of all the patients who tested positive for LTBI in Tennessee between 2002 and 2006, only $53 \%$ of those offered treatment began taking it and only $54 \%$ of those who started treatment completed it (24). Furthermore, a recent meta-analysis of 58 studies, mainly from high-income countries and published between 1946 and 2015, showed that only about $30 \%$ of those with LTBI who were offered treatment started it and only $18.8 \%$ completed treatment (25). In addition, the meta-analysis estimated an acceptance rate of $62 \%$ for treatment regimens consisting of isoniazid monotherapy (25). The included studies involved a variety of treatment regimens and took place in a range of populations including contacts of patients with active TB, marginalized populations, migrants and the general population (25).

A 2016 study by the New York City Health Department found the acceptance rate of $3 \mathrm{HP}$ to be $302 / 503$ (60\%) with $92 / 503$ $(18 \%)$ choosing other treatments and the remainder refusing all treatment (26). The overall rate of treatment acceptance was similar to that previously recorded in the clinic (historical control), which had predominantly offered INH9 (26). Among those who opted for other therapies, the requirement for DOT in the clinic was the reason most often cited for declining 3HP (26).

Improving treatment completion rates is a key goal of the shorter-course regimens. In the 2006 RCT by Schechter et al., completion of both 3HP and RMP/pyrazinamide was approximately $93 \%$ (18). Martinson et al. reported a completion rate of $95.7 \%$ for $3 \mathrm{HP}$, which was higher than comparator regimens (19). In the PREVENT TB trial, $82 \%$ of patients completed therapy in the $3 \mathrm{HP}$ arm compared to $69 \%$ of those in the INH9 arm $(P<0.001)(27)$. Risk factors for non-completion included experiencing an adverse event, substance use and a history of incarceration (27). A network meta-analysis of RCTs found higher rates of completion for 3HP and INH/RMP compared to INH monotherapy (14).

Observational studies have also supported improved completion rates with the $3 \mathrm{HP}$ regimen. In New York City Health Department TB clinics, 196/302 (65\%) of patients completed their regimen of $3 \mathrm{HP}$ compared to $42 / 92$ (46\%) who opted for other treatment $(P<0.01)$ which was higher than the $34 \%$ in historical controls $(P<0.01)$ (26). Among those incarcerated in California, 77/91 (85\%) patients completed 3HP compared to 28/154 (18\%) who completed INH9 (28). In an observational study at an American community health centre, 35/45 (78\%) of patients in the $3 \mathrm{HP}$ arm and $49 / 94$ (52\%) of patients in the INH9 arm completed treatment $(P=0.005)$ (29). The degree to which higher completion rates are driven by the use of DOT remains unclear.

\section{Adverse events}

Adverse events are another crucial component of LTBI treatment regimen selection. The PREVENT TB trial reported high rates of broadly defined hypersensitivity reactions with $3 \mathrm{HP}$ (20). However, the definition of such reactions was wide-ranging, including a combination of some 17 possible clinical criteria, and the severity of these reactions was not initially defined (20). Based on concerns about such reactions, the Canadian Tuberculosis Standards recommends the regimen be used only under closely monitored circumstances (6). In 2015, Sterling 
et al. published a more detailed analysis of the adverse events in the PREVENT TB trial, clarifying this issue (30). Systemic drug reactions were more common in the $3 \mathrm{HP}$ regimen than the INH9 regimen, with rates of $138 / 3,893(3.5 \%)$ and $15 / 3,659(0.4 \%)$, respectively $(P<0.001)(30)$. However, these reactions were mostly a flu-like syndrome (63\%) and cutaneous reactions $(17 \%)$ (30). Severe reactions were rare $(0.3 \%)$ and were associated with concomitant medications and White race (30). No patient developed anaphylaxis and no deaths were attributable to medication (30).

Reporting of adverse events was limited in early trials of $3 \mathrm{HP}$ $(18,19)$. However, rates of hepatotoxicity among patients taking 3 HP have been lower than comparators in all RCTs (18-21). In the PREVENT TB trial, 18/4,040 (0.4\%) patients in the $3 \mathrm{HP}$ arm versus $103 / 3,759$ (2.7\%) in the INH9 arm developed hepatotoxicity (20). An unpublished post-marketing study monitoring 2,134 patients taking $3 \mathrm{HP}$ in the United States found the side effect profile to be similar to that in the PREVENT TB trial $(20,31)$. Fevers and chills were reported in 126/2,134 (6\%) and myalgia or arthralgia in $148 / 2,134$ (7\%) (31). Hepatotoxicity occurred at a rate of $10 / 2,134$ (0.5\%). In an incarcerated population, 5/91 (5.5\%) developed transient fever and chills (28). A recent systematic review of the adverse events associated with $3 \mathrm{HP}$ found that rates of adverse events of this regimen compared favourably to those of other LTBI treatments but with higher rates of flu-like reactions and less hepatotoxicity (32). A comparison of INH9 and $3 \mathrm{HP}$ is summarized in Table 1.

Table 1: The treatment schedule, acceptance, completion and adverse event rates of isoniazid (INH) and INH plus rifapentine (3HP)

\begin{tabular}{|l|l|l|l|l|c|c|}
\hline \multicolumn{1}{|c|}{ Drug } & $\begin{array}{c}\text { Dosing } \\
\text { schedule }\end{array}$ & Observed? & $\begin{array}{c}\text { Acceptance } \\
\text { rate }\end{array}$ & $\begin{array}{c}\text { Completion } \\
\text { Rate }\end{array}$ & $\begin{array}{c}\text { Rate of } \\
\text { systemic } \\
\text { drug } \\
\text { reactions }\end{array}$ & Hepatotoxicity \\
\hline $\begin{array}{l}\text { Isoniazid } \\
\text { (INH9) }\end{array}$ & $\begin{array}{l}\text { Daily } \\
\text { dose } \\
\text { for } 9 \\
\text { months }\end{array}$ & $\begin{array}{l}\text { No. Self- } \\
\text { administered }\end{array}$ & $62 \%^{1}(26)$ & $\begin{array}{c}18-69 \% \\
(27-30)\end{array}$ & $0.4 \%(31)$ & $2.7 \%(20)$ \\
\hline $\begin{array}{l}\text { INH+ } \\
\text { rifapentine } \\
(3 \mathrm{HP})^{2}\end{array}$ & $\begin{array}{l}\text { Weekly } \\
\text { dose } \\
\text { for } 12 \\
\text { weeks }\end{array}$ & $\begin{array}{l}\text { Yes. Directly } \\
\text { observed } \\
\text { treatment. }\end{array}$ & $60 \%(27)$ & $\begin{array}{c}65 \%-95 \% \\
(18,19, \\
27-30)\end{array}$ & $3.5 \%(31)$ & $0.4 \%(20)$ \\
\hline
\end{tabular}

Some patie

nine months

${ }^{2}$ Note: The 3HP treatment regime is not yet authorized for use in Canada

\section{Treatment cost-effectiveness}

To our knowledge, the cost-effectiveness of 3HP in Canada has not yet been evaluated. A 2013 cost-effectiveness analysis in the United States found that over 20 years $3 \mathrm{HP}$ cost an additional US\$4,294 to $\$ 21,525$ per TB case prevented and an additional US\$911 to $\$ 4,565$ per quality-adjusted life year than INH9 (33). However, an update incorporating new, lower prices for rifapentine substantially altered this evaluation and, in fact, demonstrated cost savings compared to the price of INH9 (34). A recent study from Taiwan also demonstrated cost savings (35). However, differences in health systems, geography and local economic factors make generalization of cost-effectiveness studies between countries difficult (36). This highlights the need for high quality cost-effectiveness studies of LTBI treatment specific to the Canadian context.

\section{Conclusion}

While TB remains a challenge in Canada, particularly among foreign-born and Indigenous populations, newer regimens offer expanded options for the treatment of LTBI. Compared to the standard regimen of daily INH for nine months, a regimen of the more recent $3 \mathrm{HP}$ is shorter, equally effective, with improved completion rates and a generally favourable adverse effect profile. However, uncertainty remains with respect to acceptance and completion rates given the current use in the DOT setting as well as the role for self-administered therapy and the impact of the regimen in remote communities. The cost-effectiveness within the Canadian context has not been established. Several ongoing trials will help to answer these questions. A study comparing the adherence to self-administered versus directly observed 3HP has been completed (37), but not yet reported. The Taima TB: 3HP study, which is currently recruiting in lqaluit, Nunavut, will examine the acceptance and completion rates of $3 \mathrm{HP}$ versus those of the 9-month, twice weekly INH regimen that is standard in the territory (38). A trial in Ottawa will attempt to compare the acceptance and completion of $3 \mathrm{HP}$ and INH9 in an urban Canadian setting with a high proportion of foreign-born residents. Such trials will help to clarify the optimal role of the $3 \mathrm{HP}$ regimen, in anticipation of the regimen's authorization for use in Canada.

\section{Conflict of interest}

Dr. Alvarez is the principal investigator of the Taima TB 3HP study in lqaluit and Ottawa. Dr. Amaratunga is the site investigator for the Ottawa arm of the Taima TB 3HP study.

\section{Contributions}

Authors: GGA, CP, KRA wrote, reviewed and edited the manuscript.

\section{References}

1. Tuberculosis in Canada 2014 - Pre-release [Internet]. Ottawa: Public Health Agency of Canada; 2016 [cited 2016 Dec 31]. Available from: http://healthycanadians.gc.ca/publications/ diseases-conditions-maladies-affections/tuberculosis-2014tuberculose/index-eng.php\#a1.

2. Global tuberculosis report 2016 [Internet]. Geneva: World Health Organization; 2016 [cited 2016 Dec 31]. Available from: http://apps.who.int/iris/bitstre am/10665/250441/1/9789241565394-eng.pdf?ua=1g. pdf?ua=1.

3. Lönnroth K, Migliori GB, Abubakar I, D'Ambrosio L, de Vries G, Diel R, Douglas P, Falzon D, Gaudreau MA, Goletti D, González Ochoa ER, LoBue P, Matteelli A, Njoo H, Solovic I, Story A, Tayeb T, van der Werf MJ, Weil D, Zellweger JP, Abdel Aziz M, Al Lawati MR, Aliberti S, Arrazola de Oñate W, Barreira D, Bhatia V, Blasi F, Bloom A, Bruchfeld J, Castelli F, Centis R, Chemtob D, Cirillo DM, Colorado A, Dadu A, Dahle UR, De Paoli L, Dias HM, Duarte R, Fattorini L, Gaga M, Getahun H, Glaziou P, Goguadze L, Del Granado M, 
Haas W, Järvinen A, Kwon GY, Mosca D, Nahid P, Nishikiori N, Noguer I, O'Donnell J, Pace-Asciak A, Pompa MG, Popescu GG, Robalo Cordeiro C, Rønning K, Ruhwald M, Sculier JP, Simunović A, Smith-Palmer A, Sotgiu G, Sulis G, Torres-Duque CA, Umeki K, Uplekar M, van Weezenbeek C, Vasankari T, Vitillo RJ, Voniatis C, Wanlin M, Raviglione MC. Towards tuberculosis elimination: an action framework for low-incidence countries. Eur Respir J. 2015;45:928-52. doi: 10.1183/09031936.00214014.

4. Mack U, Migliori GB, Sester M, Rieder HL, Ehlers S, Goletti D, Bossink A, Magdorf K, Hölscher C, Kampmann B, Arend SM, Detjen A, Bothamley G, Zellweger JP, Milburn H, Diel R, Ravn P, Cobelens F, Cardona PJ, Kan B, Solovic I, Duarte R, Cirillo DM, C. Lange, TBNET. LTBI: latent tuberculosis infection or lasting immune responses to $M$. tuberculosis? A TBNET consensus statement. Eur Respir J. 2009;33(5):956-73. doi: 10.1183/09031936.00120908.

5. Comstock GW, Livesay VT, Woolpert SF. The prognosis of a positive tuberculin reaction in childhood and adolescence. Am J Epidemiol. 1974;99(2):131-8.

6. Menzies D, Alvarez GG, Khan K. Canadian tuberculosis standards, 7th ed. Ottawa: Public Health Agency of Canada; 2014. Chapter 6, Treatment of latent tuberculosis infection; $p$. 125-52. Available from: http://www.phac-aspc.gc.ca/tbpc-latb/ pubs/tb-canada-7/tb-standards-tb-normes-ch6-eng.php.

7. Lobue $P$, Menzies D. Treatment of latent tuberculosis infection: an update. Respirology. 2010:15(4);603-22.

8. Comstock GW, Ferebee SH, Hammes LM. A controlled trial of community-wide isoniazid prophylaxis in Alaska. Am Rev Respir Dis. 1967;95:935-43.

9. Li J, Munsiff SS, Tarantino T, Dorsinville M. Adherence to treatment of latent tuberculosis infection in a clinical population in New York City. Int J Infect Dis. 2010;14(4):e2927. doi: 10.1016/j.ijid.2009.05.007.

10. Page KR, Sifakis F, Montes de Oca R, Cronin WA, Doherty MC, Federline L, Bur S, Walsh T, Karney W, Milman J, Baruch N, Adelakun A, Dorman SE. Improved adherence and less toxicity with rifampin vs isoniazid for treatment of latent tuberculosis. Arch Intern Med. 2006;166(17):1863-70.

11. Lardizabal A, Passannante M, Kojakali F, Hayden C, Reichman LB. Enhancement of treatment completion for latent tuberculosis infection with 4 months of rifampin. Chest. 2006;130:1712-7.

12. Randomized Clinical Trial Comparing 4RIF vs. 9INH for LTBI Treatment-effectiveness. www.clinicaltrials.gov. Available from: https://clinicaltrials.gov/ct2/show/NCT00931736.

13. Ena J, Valls V. Short-course therapy with rifampin plus isoniazid, compared with standard therapy with isoniazid, for latent tuberculosis infection: a meta-analysis. Clin Infect Dis. 2005;40(5):670-6.

14. Pease C. et al. Efficacy and completion rates of rifapentine and isoniazid (3HP) compared to other treatment regimens for latent tuberculosis infection: a systematic review with network meta-analyses. (Submitted for publication).

15. Neu HC. Antibacterial activity of DL 473, a C3-substituted rifamycin derivative. Antimicrob Agents Chemother. 1983;24:457-60.

16. Vernon A, Burman W, Benator D, Khan A, Bozeman L. Acquired rifamycin monoresistance in patients with HIV- related tuberculosis treated with once-weekly rifapentine and isoniazid. Lancet. 1999;353:1843-7.

17. Menzies D, Elwood K. Canadian tuberculosis standards, 7th ed. Ottawa: Public Health Agency of Canada; 2014. Chapter 5: Treatment of tuberculosis disease; p. 97-124. Available from: Available from: http://www.phac-aspc.gc.ca/tbpc-latb/ pubs/tb-canada-7/tb-standards-tb-normes-ch5-eng.php.

18. Schechter M, Zajdenverg R, Falco G, Barnes GL, Faulhaber JC, Coberly JS, Moore RD, Chaisson RE. Weekly rifapentine/ isoniazid or daily rifampin/pyrazinamide for latent tuberculosis in household contacts. Am J Respir Crit Care Med. 2006;173:922-6.

19. Martinson NA, Barnes GL, Moulton LH, Msandiwa R, Hausler $H$, Ram M, Mclntyre JA, Gray GE, Chaisson RE. New regimens to prevent tuberculosis in adults with HIV infection. N Engl J Med. 2011;365(1):11-20.

20. Sterling TR, Villarino ME, Borisov AS, Shang N, Gordin F, Bliven-Sizemore E, Hackman J, Hamilton CD, Menzies D, Kerrigan A, Weis SE, Weiner M, Wing D, Conde MB, Bozeman L, Horsburgh CR Jr, Chaisson RE; TB Trials Consortium PREVENT TB Study Team. Three months of rifapentine and isoniazid for latent tuberculosis infection. N Engl J Med. 2011;365(23):2155-66.

21. Villarino ME, Scott NA, Weis SE, Weiner M, Conde MB, Jones B, Nachman S, Oliveira R, Moro RN, Shang N, Goldberg SV, Sterling TR; International Maternal Pediatric and Adolescents AIDS Clinical Trials Group; Tuberculosis Trials Consortium. Treatment for preventing tuberculosis in children and adolescents. JAMA Pediatr. 2015;169(3):247-55. doi: 10.1001/ jamapediatrics.2014.3158.

22. Sharma SK, Sharma A, Kadhiravan T, Tharyan P. Rifamycins (rifampicin, rifabutin and rifapentine) compared to isoniazid for preventing tuberculosis in HIV-negative people at risk of active TB. Cochrane Database Syst Rev. 2013;(7):Cd007545. doi:10.1002/14651858.CD007545.pub2.

23. Stagg HR, Zenner D, Harris RJ, Muñoz L, Lipman MC, Abubakar I. Treatment of latent tuberculosis infection a network meta-analysis. Ann Intern Med. 2014;161:419-28.

24. Cain KP, Garman KN, Laserson KF, Ferrousier-Davis OP, Miranda AG, Wells CD, Haley CA. Moving toward tuberculosis elimination: implementation of statewide targeted tuberculin testing in Tennessee. Am J Respir Crit Care Med. 2012;186:273-9. doi: 10.1164/rccm.201111-2076OC.

25. Alsdurf H, Hill PC, Matteelli A, Getahun H, Menzies D. The cascade of care in diagnosis and treatment of latent tuberculosis infection: a systematic review and meta-analysis. Lancet Infect Dis. 2016:16(11):1269-78. doi:10.1016/S14733099(16)30216-X.

26. Stennis NL, Burzynski JN, Herbert C, Nilsen D, Macaraig M. Treatment for tuberculosis infection with 3 months of isoniazid and rifapentine in New York City Health Department clinics. Clin Infect Dis. 2016;62(1):53-9. doi: 10.1093/cid/civ766.

27. Moro RN, Borisov AS, Saukkonen J, Khan A, Sterling TR, Villarino ME, Scott NA, Shang N, Kerrigan A, Goldberg SV. Factors associated with noncompletion of latent tuberculosis infection treatment: experience from the PREVENT TB trial in the United States and Canada. Clin Infect Dis. 2016;62:1390400. doi: 10.1093/cid/ciw126. 
28. Juarez-Reyes M, Gallivan M, Chyorny A, O'Keeffe L, Shah NS. Completion rate and side-effect profile of three-month isoniazid and rifapentine treatment for latent tuberculosis infection in an urban county jail. Open Forum Infect Dis. 2016;3(1):ofv220. doi: 10.1093/ofid/ofv220.

29. Lines G, Hunter P, Bleything S. Improving treatment completion rates for latent tuberculosis infection: a review of two treatment regimens at a community health center. J Health Care Poor Underserved. 2015;26:1428-39. doi: 10.1353/hpu.2015.0126.

30. Sterling TR, Moro RN, Borisov AS, Phillips E, Shepherd G, Adkinson NF, Weis S, Ho C, Villarino ME; Tuberculosis Trials Consortium. Flu-like and other systemic drug reactions among persons receiving weekly rifapentine plus isoniazid or daily isoniazid for treatment of latent tuberculosis infection in the PREVENT tuberculosis study. Clin Infect Dis. 2015;61:527-35. doi: 10.1093/cid/civ323.

31. Ho C. Programmatic experience with the 12 dose isoniazid/ rifapentine in the US: the Post-marketing Project. Paper presented at: Stronger together: Stopping TB from laboratory to clinic. Proceedings of the 18th Annual Conference of the Union-NAR. 2014 Feb 27-Mar 1; Boston, Massachusetts, USA.

32. Pease C. et al. A systematic review of adverse events of rifapentine and isoniazid compared to other treatment regimens for latent tuberculosis infection. (Submitted for publication).
33. Shepardson D, Marks SM, Chesson H, Kerrigan A, Holland DP, Scott N, Tian X, Borisov AS, Shang N, Heilig CM, Sterling TR, Villarino ME, Mac Kenzie WR. Cost-effectiveness of a 12dose regimen for treating latent tuberculous infection in the United States. Int J Tuberc Lung Dis. 2013;17(12):1531-7. doi: 10.5588/ijtld.13.0423.

34. Shepardson D, MacKenzie WR. Update on cost-effectiveness of a 12-dose regimen for latent tuberculous infection at new rifapentine prices. Int J Tuberc Lung Dis. 2014;18(6):751. doi: 10.5588/ijtld.14.0052.

35. Huang YW, Yang SF, Yeh YP, Tsao TC, Tsao SM. Impacts of 12-dose regimen for latent tuberculosis infection: treatment completion rate and cost-effectiveness in Taiwan. Medicine (Baltimore). 2016;95(34):e4126. doi: 10.1097/ MD.0000000000004126.

36. Sculpher MJ, Pang FS, Manca A, Drummond MF, Golder $\mathrm{S}$, Urdahl H, Davies LM, Eastwood A. Generalisability in economic evaluation studies in healthcare. Health Technol Assess. 2004;8(49): iii-iv, 11-192.

37. Study 33: Adherence to Latent Tuberculosis Infection Treatment 3HP SAT Versus 3HP DOT (iAdhere). www. clinicaltrials.gov. Available from: https://clinicaltrials.gov/ct2/ show/NCT01582711?term=rifapentine\&rank=24.

38. Taima TB: 3HP Study. www.clinicaltrials.gov. Available from: https://clinicaltrials.gov/ct2/show/NCT02689089?term=rifape ntine\&rank=27.

\title{
The definitive resource on diagnosis and treatment:
}

\author{
Canadian \\ Tuberculosis \\ Standards \\ $7^{\text {th Edition }}$
}

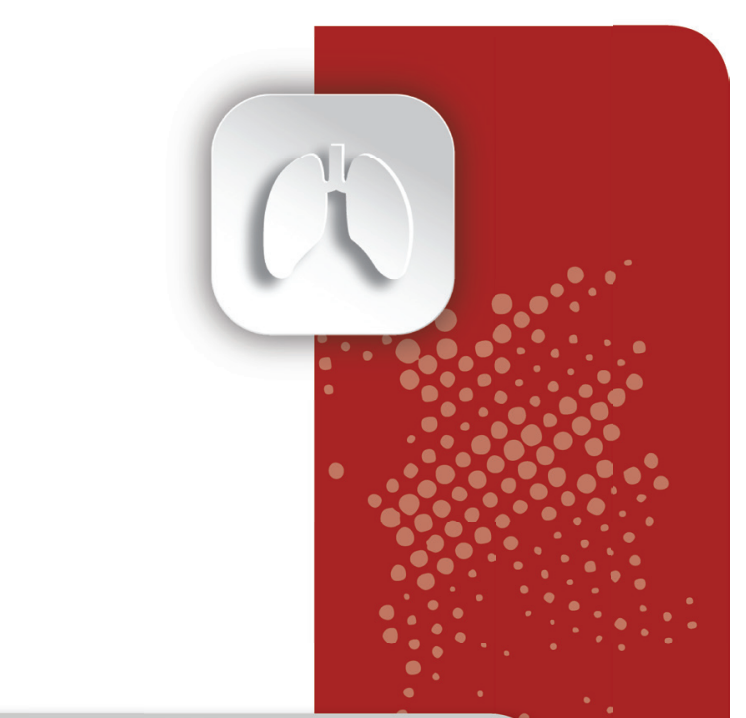

Free PDF available for download

Web search: Canadian TB Standards

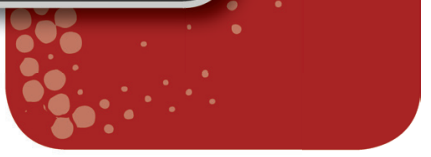

